\title{
Research on the Service Ability of CALIS Institutional Repository to University Scientific Research
}

\author{
Haiyan chen \\ Library of Central China Normal University, Wuhan, P.R.China, \\ chenhy@mail.ccnu.edu.cn
}

Keywords: CALIS IR(institutional repository); resource organization; research data management

\begin{abstract}
This paper, by introducing the construction on institutional repository of university alliance of CALIS, the author describes the system and platform construction, standard construction and resource construction of CALIS institutional repository. This paper studies the support of CALIS institutional repository for university research in scientific research, data management, knowledge discovery and academic communication.
\end{abstract}

\section{Introduction}

In 21Century, produced huge influence to the development of grid technology and open source technologies on the Internet, institutional repository becomes the newly emerging things based on these research achievements. Some university have established by the development of university academic database for the purpose of the institutional repository. It promotes the university library in the trend of knowledge base construction, and plays a role of convening, organizing and implementing.

\section{The Background of CALIS Institutional Repository}

The development of institutional repository have a close relationship with the great open access movement, open access is the international academic circles, the dissemination of information, the publishing industry using the network communication to promote scientific research achievements and the movement of the open access movement, popular in the world within the scope of the construction and the development of institutional repository keep a high-speed situation. According to Open DOAR statistics, by the end of June 21, 2010, the number of institutional repositories worldwide registered on this site to 1375, the number was increased to 1980 on July 5, 2011, and to 2161 on June 1, 2012[2].

\section{CALIS Institutional Repository Start}

Comparing to abroad library, the construction of Chinese institutional repository, especially the Mainland university institutional repository is relatively slow in development. Before 2011, in addition to 20 several institutional repositories which were registered by Chinese Academy of Sciences, University Institutional Repository of Xiamen University was only a registered institution on the Open DOAR website. After years later, CALIS launched a university library alliance to develop the construction of their own institutional repository, which makes the China institutional repository development has improved.

In August 2011, CALIS officially launched the three phase of institutional repository projects, the establishment of project management group and technical implementation group, determine the technical scheme and task division "management coordination system"[2], led by Peking University, started the construction of the project, on April 27,2012, the project formally adopted by the approval. There are 33 University Library Construction and release their institutional repositories of library currently. By July 2015, 40 University Libraries have completed the IR registration at the CALIS institutional repository platform. 


\section{CALIS Institutional Repository}

\section{The Concept of CALIS IR}

CALIS institutional repository that is called CALIS IR for shot, is an institutional repository of University. A university institutional repository is the establishment of digital resource storage which collect, preserve and centralized comprehensive system. It reflects the school scientific research achievements, at the same time, establish academic resources network service platform for a series of services that provide to the staff and students integrity, unity, authority and open access , managing and publishing, digital data generated by the organization and its members. Institutional repository is the infrastructure of academic research in Universities in the digital age [1].

\section{Position of CALIS IR}

CALIS IR is defined a university institutional repository, only academic resources collection, resources storage and resources release. The collection, preservation, management and utilization of resources depend on the network environment, and can be integrated with other knowledge system online. Academic resources are convenient to use and search. The preservation and publication and publication of the research results are cumulative, long-term and dynamic.

\section{The Role of CALIS IR}

Institutional repository is an academic resource infrastructure for academic research in universities. It collects, exhibits, shares, manages and saves research results, improves the visibility of colleges and Universities, the academic reputation of individuals, attracting more research funds and students and teachers. Institutional repository promotes free use and free access of all kinds of achievements, promotion of application efficiency and scientific research achievements. Analyze and evaluate the research direction, process, trend and result of mechanism. It realizes to scientific research management of scientific research personnel, and be convenient for the school hold and management of teaching and research activities on macroscopic. For individual, institutional repository is convenient for the accumulation, evaluation, reporting, awards and achievements of individual scientific research.

\section{The Construction of CALIS IR}

In 2011, CALIS started the construction of organization of University Library Alliance Development of institutional repository in its three periods. On the basis of the existing research results, the databases of university library which were joined the union was standardized and developed further. These existing research results transited rapidly to the IR, forming knowledge service for teaching and scientific research in further expansion .

\section{System Construction}

CALIS IR was developed three systems: project construction as library of Peking University is responsible for the development of institutional repository center completed the CALIS system(CHAIR Central); Peking University library, Beijing Institute of Technology library, Tsinghua University library and Xiamen University library jointly developed CALIS IR local system(CHAIR local version)[2]; in addition, Chongqing University library development another version of CALIS IR local system HAIR RISE version). According to the demand of the localization, the open source platform DSpace is necessary and effective function expansion and development, combined with the application of technology of a number of open-source software, has realized the DSpace Chinese localization and a number of personalized expansion function. Institutional Repository independent development platform even more interlinks into the idea of Web 2.0. It enhances multimedia management and Web 2.0 elements, provides personal center, tags, comments, RSS and other functions, effectively improve the user experience.

\section{Standard Specification Construction}

CALIS IR made the key investment and construction in the establishment of the standards this period, making the completion of a series of standards, has completed the "metadata description specification", "institutional repository construction guide", "institutional repository system requirements specification", "mechanism of knowledge base system design manual”, "mechanism 
knowledge base system user manual", "institutional repository system implementation Deployment Handbook "etc. The construction of the project follows the Standard Specification for DC metadata, in order to ensure the ability of the system platform and long-term sustainable development, for future data harvesting and interactive sharing basis.

\section{Resource Construction}

In the resources construction, CALIS IR almost comprehensive and extensive collection of various types of academic achievements, mainly for the published academic papers and monographs, theses and dissertations, conference papers, postdoctoral reports, investigation reports. Peking University Library also income quality courses, lectures, Peking University unpublished preprint report, the other pavilions also collected a feature of the school's academic achievements that is not easy to collect. On collection objects, in addition to teachers and students, they also pay more attention to the well-known scholars, digital on their academic achievements in scientific research, improve the group collection system. Some colleges and universities library also collected for the exchange of scholars in the school during the work of scientific research achievements.

The cut-off project approval, the construction hall total completed various resource types 76178, which includes books, journal articles, conference papers, research reports, dissertations and other resource types in common, including photos, pictures, audio and video project, documentary film, computer software and other special resource type [2].

CALIS IR construction project also explored the work mode of multi library collaborative development, and achieved remarkable results. Technology platform is cooperative developed by the five demonstration libraries, which can complete the research and developed three sets of system in a short time. And the realization of the source code is completely open and sharing. It provides successful experiences of platform construction and application of institutional repository system for the library industry.

\section{Service Platform Construction}

CALIS IR project group develop the institutional repository service platform, that more integrated into the concept Web2.0, to provide personal center, tags, comments, RSS and other functions. In addition, also vigorously develop the personalized service function, effectively improve the user experience, to attract readers to use the institutional repository. For example, Zhejiang University library's IR page provides document download rankings, recently recommended resources, academic achievement distribution map, personal space etc., which are more adapted to user demand behavior and personalized services, comprehensively close to the user services to improve the use efficiency of institutional repository.

In the mass of academic resources' management and service, CALIS IR also finds in technology with large data and resources, enhance the institutional repository construction level and service capabilities, and provides strong support for academic research.

\section{Service Ability for Scientific Research}

CALIS IR is a deeper resource organization for the University Library Association to apply modern information technology and computer network technology to the scientific research data resources of universities. It collects, classifies and indexes scientific research literature resources, and provides information transmission and sharing resource. CALIS IR's service ability cannot be confined to the surface of the platform service function, In support of scientific research, CALIS IR should vigorously expands and improves its service ability in the course of scientific research, and through various aspects of scientific research activities.

\section{CALIS IR Data Storage and Filing System}

Each member library of CALIS IR sets up good storage environment, sets up specifically for the institutional repository of data warehouse can store all types of data storage, data backup to the server regularly, ensure the long-term security of data. The degree of openness and openness of the data is limited, and the data of scientific research achievements are stored and managed centrally to achieve online access in a certain scope. The collection and use of scientific research data in the institutional repository of this institution, member library of CALIS IR have issued a deposit 
payment policy, management policy, communication policy, protecting intellectual property rights about the author, using and sharing of academic resources in the system.

\section{Research Data Management}

The research data is all that exists in a digital format object generated in the process of scientific research, including text, multimedia data results. According to the data of the lifecycle, research data management after production, description, preservation and reuse of the cycle, make the data research valuable to value added in the research data sharing, so as to promote the academic exchanges and development. While the construction of institutional repository is better to preserve knowledge achievements, and ultimately to achieve maximum value in the sharing[4]. CALIS IR has a good ability to preserve and manage all kinds of digital resources, and it can effectively manage the achievement data in the process of scientific research. At present, CALIS IR is related to scientific research data, and docking with scholars system, integrating with scientific research management system, establishing scientific research data management and service platform, and realizing management of academic research data.

\section{Knowledge Discovery in Scientific Research Data}

CALIS IR builds a web portal service platform, which integrates the institutional repositories of each member's Pavilion onto this platform for unified management. All member library of CALIS IR according to specification for unified metadata description formulation, established norms, classification, indexing, metadata description on scientific research data. CALIS IR through data harvesting, realize publishing and management of data. CALIS IR service system platform using classification and statistical analysis tools, multi-angle classification and ordination of scientific research data, help researchers find related information, effective information collection quickly organized research, accelerate the innovation of scientific research.

\section{Value Added Service of Scientific Research Service Mode}

CALIS IR develops a series of value-added services on the research service mode. Go deep into the key research group of each school, and provide the point to point discipline service. The institutional repository and scholar library are integrated to promote value-added services for scholars, resulting in a production Citation Report and a production citation notification. Using platform measurement analysis and evaluation tools, statistical analysis, visual analysis, and analysis reports can be formed, which can serve as a reference for institutional research evaluation.

\section{Conclusion}

CALIS IR is an important academic research database for academic research in University library. It can manage university research results and research data more effectively, and help researchers to facilitate the acquisition and sharing of academic resources, promote knowledge discovery and knowledge innovation, and support academic research. CALIS IR based on the members of the CALIS Museum, establishes China University Institutional Repository Sharing Alliance, forming an academic shared network, Promote academic exchanges and interdisciplinary collaborative research.

\section{References}

[1] J.Z. Wu. Library VS Institutional Repository - Rethinking in Strategic Development of Library. Journal of Library Science in China, 5(2004), p 5 8.

[2]H. Nie. CALIS Institutional Repository: Construction and Promotion, Reflection and Prospects. Journal of Library Science in China , 2(2013), p46 51 .

[3]J. Deng and H.Q. Shan. Monash University Research Data Management Practice and Enlightenment for China's Construction of the Institutional Repository. Information theory and Practice, 5(2014), p 136 139 .

[4]X.H. Li. Research Data Management and Service Pattern in Libraries. Journal of Library Science in China,5(2011),P46 52. 
[5]M.J. Ma. Institutional Repositories: a New model of Academic Exchange and Resource Sharing. Library Work in Colleges and Universities,1(2007),P10 13. 